\title{
Risk of Aplastic Anemia in Patients Using Antiepileptic Drugs
}

\author{
${ }^{*} \dagger$ Kim B. Handoko, ${ }^{*}$ Patrick C. Souverein, ${ }^{*} \ddagger$ Tjeerd P. van Staa, ${ }^{*} \oint$ Ronald H. B. Meyboom, \\ ${ }^{*}$ Hubert G. M. Leufkens, ${ }^{*}$ Toine C. G. Egberts, and *Patricia M. L. A. van den Bemt \\ * Department of Pharmacoepidemiology and Pharmacotherapy, Utrecht Institute for Pharmaceutical Sciences, Utrecht, and \\ $\dagger$ † Hospital Pharmacy “Ziekenhuisapotheek Noordoost-Brabant," 's-Hertogenbosch, The Netherlands; \\ $¥$ Medical Research Council, Environmental Epidemiology Unit, Southampton University Hospital, Southampton, United Kingdom; \\ and \$The Uppsala Monitoring Centre, WHO Collaborating Centre for International Drug Monitoring, Uppsala, Sweden
}

Summary: Purpose: To assess the association between exposure to antiepileptic drugs (AEDs) and the occurrence of aplastic anemia.

Methods: A retrospective case-control study was conducted using data from the U.K. General Practitioners Research Database (GPRD). Cases were defined as patients diagnosed with aplastic anemia. For each case, up to three control patients were matched on age, sex, and medical practice. Cases and controls were compared with respect to AED use. The effects of duration of AED use were assessed. Characteristics of individual cases with AED use were reviewed.

Results: The study population comprised 173 cases and 497 controls. AED use was more prevalent among cases $(9.2 \%)$ than among controls $(0.8 \%)$. After adjustment for confounders, the use of AEDs was significantly associated with aplastic anemia (adjusted odds ratio (OR), 9.5; 95\% confidence interval (CI), 3.0-39.7). The most frequently used AEDs were carbamazepine (CBZ), valproic acid (VPA), and phenytoin. The 16 exposed cases were heterogeneous with respect to patient and exposure characteristics: the age of these patients varied from 1 to 92 years, and the duration of AED use varied from 17 days to 6.8 years.

Conclusions: This study indicates that use of AEDs, in particular CBZ and VPA, is associated with a ninefold increased risk of aplastic anemia. Physicians should be alert to the possibility of AED-associated aplastic anemia. Key Words: Aplastic anemia-Drug-induced-Antiepileptic drugs-GPRD-Casecontrol study.
Aplastic anemia is a hematopoietic stem-cell disorder characterized by pancytopenia of the peripheral blood and hypocellular bone marrow. In its most severe form, aplastic anemia requires intensive therapy with either bone marrow transplantation or immunosuppression. Case fatality rate is approximately $10 \%$ (1).

Although aplastic anemia has an incidence of only a few cases per million per year, it is one of the most feared idiosyncratic complications of drug treatment. In addition to causing patient harm, aplastic anemia may also harm the drug: when evidence emerges that a drug is associated with aplastic anemia, regulatory agencies are reluctant to seek approval in case of a new drug, as well as inclined to withdraw an already approved drug from the market $(2,3)$.

\footnotetext{
Accepted March 3, 2006.

Address correspondence and reprint requests to Dr. P.M.L.A. van den Bemt at Department of Pharmacoepidemiology and Pharmacotherapy, Utrecht Institute for Pharmaceutical Sciences, P.O. Box 80082, 3508 TB Utrecht, The Netherlands. E-mail: p.m.l.a.vandenbemt@pharm.uu.nl doi: $10.1111 /$ j.1528-1167.2006.00596.x
}

The association between AED use and aplastic anemia has been described in several case reports (4-7). The International Agranulocytosis and Aplastic Anemia Study (IAAAS) was conducted to identify various drugs that were associated with an increased risk of agranulocytosis or aplastic anemia (8). Although carbamazepine (CBZ) and phenytoin (PHT)were suspected to be associated with aplastic anemia, the authors acknowledged they had insufficient data to evaluate this specific association with AEDs with adequate control for confounding. Blackburn et al. (9) investigated the frequency of serious blood dyscrasias, including aplastic anemia, in a cohort study among 29,357 patients taking AEDs. They found only one case of aplastic anemia and could not draw specific conclusions with respect to the association between use of antiepileptic agents and aplastic anemia.

To our knowledge, no studies have specifically investigated the relation between AEDs and aplastic anemia. Therefore the aim of our study was to assess the strength of the association between AED use and the risk of aplastic anemia. 


\section{PATIENTS AND METHODS}

We conducted a case-control study using data from the UK-based General Practice Research Database (GPRD). The GPRD contains the computerized medical records of 686 general practices in the U.K. Clinical data are stored and retrieved by means of Oxford Medical Information Systems (OXMIS) and Read codes for diseases or causes of morbidity and mortality that are cross-referenced to the International Classification of Diseases (ICD-9). The GPRD has been shown to be a useful and valid source for several observational studies, including research on the frequency of blood dyscrasias among patients taking AEDs (9), as well as a study on the risk of agranulocytosis and neutropenia associated with current drug use (10). Our study was approved by the Scientific and Ethical Advisory Group of the GPRD.

We identified all patients with a first diagnosis of aplastic anemia (ICD-9 code 284) recorded during the period from the enrollment date of their practice in GPRD up to the end of data collection (1987-2002). Cases were eligible for inclusion if they had $\geq 1$ year of history in the GPRD. Given our interest in idiosyncratic disease, patients with a history of use of chemotherapy, immunosuppressive drugs, or hormone antagonists prior to the index date were excluded. Control patients did not have a diagnosis of aplastic anemia at any time. The same inclusion and exclusion criteria were applied to controls and case patients. We matched up to three controls to each case on age (within 1 year), sex, and medical practice. The index date of each control patient was that of the matched case.

The determinant of interest in this study was exposure to AEDs. Exposure status was based on the prescription information prior to the index date. Because aplastic anemia may develop over several months after exposure to the sus- pected agent and can have a lag time before definitive diagnosis (11), we defined exposure to AEDs as a prescription for an AED within the time window of 1 year before the index date. A medical history of malignancy (i.e., without chemotherapy), systemic lupus erythematosus, myelodysplasia, megaloblastic anemia, mycobacterial infections, viral infections, or allergies were in line with available evidence considered as potential confounders $(8,12,13)$. In addition, exposure to nonantiepileptic agents that have been implicated with aplastic anemia in the medical literature $(8,12,13)$ or of which five or more case reports in relation to aplastic anemia were reported to the WHO Collaborating Centre for International Drug Monitoring (14) were also considered potential confounding factors (Appendix 1). Furthermore, characteristics of individual cases with AED use, as available in the GPRD database, were reviewed.

The strength of the association between use of AEDs and aplastic anemia was estimated by using exact conditional logistic regression analysis and expressed as odds ratios (ORs) and 95\% confidence intervals (CIs). Potential confounders were studied both in univariate models and in a multivariate model. They were included in the multivariate model if they induced $a \geq 10 \%$ change in the crude OR for the exposure of interest.

\section{RESULTS}

Of 265 patients with a first diagnosis of aplastic anemia, 92 patients did not meet our inclusion criteria (88\% because of a history in GPRD of $<1$ year). The study population comprised 173 cases with aplastic anemia and 479 matched controls. The characteristics of cases and controls are displayed in Table 1. History of malignancy, viral infection, and allergy were more frequently reported

TABLE 1. Characteristics of case patients with aplastic anemia and matched controls

\begin{tabular}{|c|c|c|c|c|c|}
\hline Characteristic & $\begin{array}{c}\text { Case }(\mathrm{n}=173) \\
\text { No }(\%)\end{array}$ & $\begin{array}{c}\text { Control }(\mathrm{n}=479) \\
\text { No }(\%)\end{array}$ & OR & $(95 \% \mathrm{CI})$ & $\mathrm{p}$ Value \\
\hline \multicolumn{6}{|l|}{ Sex } \\
\hline Male & $73(42.2)$ & $205(42.8)$ & N/A & & \\
\hline Female & $100(57.8)$ & $274(57.2)$ & & & \\
\hline \multicolumn{6}{|l|}{ Age (yr) } \\
\hline$<20$ & $22(12.7)$ & $61(12.7)$ & N/A & & \\
\hline 20-39 & $19(11.0)$ & $49(10.2)$ & & & \\
\hline $40-59$ & $35(20.2)$ & $99(20.7)$ & & & \\
\hline $60-79$ & $64(37.0)$ & $178(37.2)$ & & & \\
\hline$\geq 80$ & $33(19.1)$ & $92(19.2)$ & & & \\
\hline \multicolumn{6}{|l|}{ Comorbidity } \\
\hline Malignancy & $23(13.3)$ & $20(4.2)$ & 3.6 & $(1.8-7.4)$ & $<0.001$ \\
\hline Viral infection & $17(9.8)$ & $15(3.1)$ & 3.5 & $(1.6-8.2)$ & 0.002 \\
\hline Allergy & $9(5.2)$ & $3(0.6)$ & 7.7 & $(1.9-44.3)$ & 0.002 \\
\hline Myelodysplasia & $8(4.6)$ & $1(0.2)$ & 21.2 & $(2.8-946)$ & $<0.001$ \\
\hline \multicolumn{6}{|l|}{ Comedication } \\
\hline Betalactam antibiotics & $26(15.0)$ & $38(7.9)$ & 2.4 & $(1.3-4.6)$ & 0.006 \\
\hline Antidepressants & $14(8.1)$ & $17(3.5)$ & 2.4 & $(1.0-5.3)$ & 0.041 \\
\hline NSAIDs & $24(13.9)$ & $33(6.9)$ & 2.2 & $(1.2-4.1)$ & 0.014 \\
\hline
\end{tabular}

Matching variables: age and sex. N/A, not applicable. 
TABLE 2. Association between use of AEDs and risk of aplastic anemia

\begin{tabular}{|c|c|c|c|c|c|c|}
\hline & $\begin{array}{c}\text { Case }(\mathrm{n}=173) \\
\text { No. }(\%)\end{array}$ & $\begin{array}{c}\text { Control }(\mathrm{n}=479) \\
\text { No. }(\%)\end{array}$ & $\begin{array}{l}\text { Crude OR } \\
(95 \% \mathrm{CI})\end{array}$ & $\mathrm{p}$ Value & $\begin{array}{l}\text { Adjusted OR } \\
\quad(95 \% \mathrm{CI})\end{array}$ & $\mathrm{p}$ Value \\
\hline \multicolumn{7}{|l|}{ AED use } \\
\hline No use & $157(90.8)$ & $475(99.2)$ & 1.0 (Ref.) & & 1.0 (Ref.) & \\
\hline AED user & $16(9.2)$ & $4(0.8)$ & $10.9(3.5-45.1)$ & $<0.001$ & $9.5(3.0-39.7)$ & $<0.001$ \\
\hline \multicolumn{7}{|c|}{ AED mono- versus polytherapy } \\
\hline No AEDs & $157(90.8)$ & $475(99.2)$ & $1.0(\operatorname{Ref})$ & & $1.0(\operatorname{Ref})$ & \\
\hline AED monotherapy & $11(6.3)$ & $4(0.8)$ & $7.9(2.1-31.6)$ & $<0.001$ & $7.3(2.1-31.6)$ & $<0.001$ \\
\hline AED polytherapy & $5(2.9)$ & 0 & $16.1(2.2-\infty)$ & 0.005 & $11.2(1.3-\infty)$ & 0.025 \\
\hline \multicolumn{7}{|l|}{ Specific AED use } \\
\hline No use & $157(90.8)$ & $475(99.2)$ & 1.0 (Ref.) & & 1.0 (Ref.) & \\
\hline Any CBZ & $8(4.6)$ & $2(0.4)$ & $11.2(2.2-108)$ & 0.001 & $10.3(2.0-101)$ & 0.003 \\
\hline Any PHT & $4(2.3)$ & $2(0.4)$ & $5.3(0.8-58.7)$ & 0.107 & $3.5(0.4-44.4)$ & 0.346 \\
\hline Any VPA & $6(3.5)$ & 0 & $21.7(3.1-\infty)$ & $<0.001$ & $18.2(2.5-\infty)$ & 0.002 \\
\hline
\end{tabular}

Odds ratios were adjusted for allergy.

CBZ, Carbamazepine; PHT, phenytoin; VPA, valproic acid.

TABLE 3. Individual features of 16 AED users among cases with aplastic anemia

\begin{tabular}{|c|c|c|c|c|c|c|}
\hline Case & Age (yr) & Sex & $\begin{array}{l}\text { AED in year } \\
\text { before index date }\end{array}$ & $\begin{array}{l}\text { Duration of last } \\
\text { AED regimen (days) }\end{array}$ & $\begin{array}{l}\text { AED after } \\
\text { index date }\end{array}$ & $\begin{array}{l}\text { Potential } \\
\text { confounders }\end{array}$ \\
\hline 1 & 1 & $\mathrm{~F}$ & Carbamazepine & 26 & Continue carbamazepine & - \\
\hline 2 & 8 & M & Vigabatrin and phenytoin & 69 & $\begin{array}{l}\text { Vigabatrin and } \\
\text { phenytoin: stop } \\
\text { Switch to clonazepam, } \\
\text { gabapentin, topiramate, and } \\
\text { ethosuximide }\end{array}$ & - \\
\hline 3 & 20 & $\mathrm{~F}$ & Carbamazepine & 174 & $\begin{array}{l}\text { Carbamazepine: stop } \\
\text { No AEDs }\end{array}$ & $\begin{array}{l}\text { Use of betalactam } \\
\text { antibiotics and } \\
\text { antidepressants }\end{array}$ \\
\hline 4 & 33 & M & $\begin{array}{l}\text { Lamotrigine, valproic acid, } \\
\text { and primidone }\end{array}$ & 927 & $\begin{array}{l}\text { Valproic acid: stop } \\
\text { Continue lamotrigine } \\
\text { and primidone }\end{array}$ & - \\
\hline 5 & 39 & $\mathrm{~F}$ & Phenytoin and carbamazepine & 299 & $\begin{array}{l}\text { Carbamazepine and } \\
\text { phenytoin: stop } \\
\text { Switch to Gabapentin }\end{array}$ & $\begin{array}{l}\text { Recorded urticaria, } \\
\text { allergic rash }\end{array}$ \\
\hline 6 & 40 & M & Carbamazepine & 129 & $\begin{array}{l}\text { Carbamazepine: stop } \\
\text { No AEDs }\end{array}$ & - \\
\hline 7 & 43 & M & Valproic acid & 1,106 & $\begin{array}{l}\text { Valproic acid: stop } \\
\text { Start: phenytoin, } \\
\text { vigabatrin, lamotrigine, and } \\
\text { carbamazepine }\end{array}$ & - \\
\hline 8 & 50 & $\mathrm{~F}$ & $\begin{array}{l}\text { Valproic acid and } \\
\text { carbamazepine }\end{array}$ & 107 & $\begin{array}{l}\text { Carbamazepine and valproic acid: stop } \\
\text { No AEDs }\end{array}$ & $\begin{array}{l}\text { Use of betalactam } \\
\text { antibiotics and } \\
\text { antidepressants }\end{array}$ \\
\hline 9 & 61 & $\mathrm{~F}$ & Valproic acid & 1,205 & Continue valproic acid & - \\
\hline 10 & 68 & $\mathrm{~F}$ & Carbamazepine & 1,291 & $\begin{array}{l}\text { Carbamazepine: stop } \\
\text { No AEDs }\end{array}$ & - \\
\hline 11 & 70 & $\mathrm{~F}$ & Phenytoin & 235 & Continue phenytoin & - \\
\hline 12 & 71 & M & Carbamazepine & 57 & $\begin{array}{l}\text { Carbamazepine: stop } \\
\text { No AEDs }\end{array}$ & - \\
\hline 13 & 73 & M & Carbamazepine & 113 & $\begin{array}{l}\text { Carbamazepine: stop } \\
\text { No AEDs }\end{array}$ & $\begin{array}{l}\text { Use of betalactam } \\
\text { antibiotics and } \\
\text { antidepressants }\end{array}$ \\
\hline 14 & 75 & $\mathrm{~F}$ & Valproic acid & 638 & Continue valproic acid & - \\
\hline 15 & 81 & $\mathrm{~F}$ & Phenytoin and phenobarbital & 2,872 & $\begin{array}{l}\text { Phenytoin and phenobarbital: stop } \\
\text { No AEDs }\end{array}$ & - \\
\hline 16 & 92 & $\mathrm{~F}$ & Valproic acid & 2,492 & $\begin{array}{l}\text { Valproic acid: stop } \\
\text { No AEDs }\end{array}$ & $\begin{array}{l}- \\
-\end{array}$ \\
\hline
\end{tabular}


in the case group than in the control group, as were current use of betalactam antibiotics, antidepressants, and nonsteroidal antiinflammatory drugs (NSAIDs). Other determinants were not significantly associated with aplastic anemia (data not shown).

Overall, exposure to AEDs was more prevalent among cases $(9.2 \%)$ than among controls $(0.8 \%)$, yielding a crude OR of 10.9 (95\% CI, 3.5-45.1). After adjustment for confounders, the OR was lower but still clearly increased (adjusted OR, 9.5; 95\% CI, 3.0-39.7). Polytherapy with AEDs was more strongly associated with aplastic anemia than was monotherapy (Table 2).

Of the 16 patients that were users of AEDs (Table 3), eight used CBZ (OR, 10.3; 95\% CI, 2.0-101), six used VPA (OR, 18.2; 95\% CI, 2.5- $\infty$ ), and four used PHT (OR, 3.5 ; 95\% CI, 0.4-44.4) during the year before the index date. The cases were rather heterogeneous with respect to age (range, 1-92 years) and duration of AED exposure (range, 17 days to 6.8 years). For the latter, we chose the duration of the last AED regimen. After aplastic anemia was recorded, four patients continued their AED therapy, two patients switched to other AEDs, and eight patients discontinued AED therapy.

\section{DISCUSSION}

In this study, we found that exposure to AEDs was associated with a ninefold increased risk of aplastic anemia.

Several case reports described a possible association between AED use and aplastic anemia, felbamate (FBM) being the most frequently reported AED involved. In our study population, none of the cases and the controls used FBM, which could be explained by the study period (up to 2002). Use of CBZ and VPA was significantly associated with aplastic anemia in our study. After aplastic anemia had been diagnosed, the AED regimen was changed in most patients, presumably indicating that physicians suspected the AED to be responsible for aplastic anemia.

The pathophysiology of acquired aplastic anemia is thought to be immune mediated. Since Palace and Lang (15) hypothesized that autoimmune mechanisms might have an etiologic role in patients with epilepsy, one could argue that our results could be explained by the underlying disease instead of the AED. However, evidence supporting this hypothesis is not yet available in the literature.

This study should be seen in light of its limitations. AEDs have been associated with several blood dyscrasias $(8,9)$. Therefore diagnostic suspicion bias could be a problem with aplastic anemia because clinicians often make the diagnosis based on the drug-exposure history. This could lead to an absolute risk overestimation. It is possible that patients with aplastic anemia died before being diagnosed. This would have resulted in an underestimation of the true risk estimate. Furthermore, the coding of the outcome event may have been inaccurate. We did not perform a validation of cases. Van Staa et al. (10) validated cases of neutropenia and agranulocytosis in the GPRD by sending questionnaires to the general practitioners (GPs): the diagnosis was confirmed in $94.6 \%$ and $97.1 \%$ of cases, respectively. Aplastic anemia is a laboratory-based diagnosis as well, but requires additional bone marrow examination. We cannot exclude the possibility of some misclassification, but it seems unlikely that this can explain the large effect we observed.

To our knowledge, this study is one of the few epidemiologic studies on aplastic anemia and AED exposure. Most of what is known or suspected about this association is based on case reports. We used data up to 2002, whereas the last epidemiologic study on AEDs and blood dyscrasias used data up until 1994 (9). We adjusted for confounding by taking into account comorbidities associated with aplastic anemia and other potentially causal drugs, including the latest registrations in the WHO database.

CBZ and VPA are the most widely prescribed AEDs. However, the relative risk for aplastic anemia in other AEDs may be comparable. Thus further research is needed to study whether use of newer AEDs (besides FBM) such as topiramate, levetiracetam, and gabapentin, is associated with the occurrence of aplastic anemia. It would be interesting to study whether use of AEDs is associated with other immune-modulated hematologic adverse events, such as pure red cell aplasia.

In conclusion, our study adds to the limited evidence on the association between exposure to AEDs and aplastic anemia. Thus physicians should be alert to the possibility of AED-associated aplastic anemia.

APPENDIX 1. Potential confounders $(8,12,13,14)$

\begin{tabular}{lll}
\hline Diseases & \multicolumn{2}{c}{ Prescription drugs } \\
\hline Cancer & ACE inhibitors & Disease-modifying \\
Leukemia & Allopurinol & antirheumatic drugs \\
Lymphoma & Amphotericin B & $\mathrm{H}_{2}$ antagonists \\
Megaloblastic anemia & Antidepressive & Macrolide antibiotics \\
Mycobacterial infections & drugs & Mebendazole \\
Myelodysplasia & Antipsychotics & Nitrofurantoin \\
Systemic lupus & Antithyroid & NSAIDs \\
erythematosus & medication & Oral antidiabetics \\
Viral infections & Azoles & Proton-pump inhibitors \\
& $\beta$ Blockers & Quinolones \\
Other & Betalactam & Statins \\
\hline Allergies & antibiotics & Sulfasalazine \\
Pesticides & Calcium & Thiazides \\
& antagonists & Trimethoprim/ \\
& Carboanhydrase & sulfamethoxazole \\
& inhibitors & Vaccines \\
& Chloramphenicol & \\
& Clopidrogrel & \\
& Clozapine & \\
\hline & Digoxin & \\
& & \\
& & \\
& &
\end{tabular}


Acknowledgment: We thank Dr. Jeannette Zwart-van Rijkom and Dr. Walter Hermens for the useful comments on our paper.

\section{REFERENCES}

1. Tichelli A, Gratwohl A, Wursch A, et al. Late haematological complications in severe aplastic anaemia. Br J Haematol 1988; 69:4138.

2. Man Fung F, Thornton A, Mybeck K, et al. Evaluation of the characteristics of safety withdrawal of prescription drugs from worldwide pharmaceutical markets-1960 to 1999. Drug Info J 2001; 35:293317.

3. Young NS. Acquired aplastic anemia. Ann Intern Med 2002; 136:534-46.

4. Acharya S, Bussel JB. Hematologic toxicity of sodium valproate. $J$ Pediatr Hematol Oncol 2000; 22:62-5.

5. Blain H, Hamdan KA, Blain A, et al. Aplastic anemia induced by phenytoin: a geriatric case with severe folic acid deficiency. $J \mathrm{Am}$ Geriatr Soc 2002; 50:396-7.

6. Franceschi M, Ciboddo G, Truci G, et al. Fatal aplastic anemia in a patient treated with carbamazepine. Epilepsia 1988; 29:582-3.

7. Kaufman DW, Kelly JP, Anderson T, et al. Evaluation of case reports of aplastic anemia among patients treated with felbamate. Epilepsia 1997; 38:1265-9.

8. Kaufman DW KJ, Levy M, Shapiro S. The drug etiology of agranulocytosis and aplastic anemia. New York: Oxford University Press, 1991.

9. Blackburn SC, Oliart AD, Garcia Rodriguez LA, et al. Antiepileptics and blood dyscrasias: a cohort study. Pharmacotherapy 1998 18:1277-83.

10. van Staa TP, Boulton F, Cooper C, et al. Neutropenia and agranulocytosis in England and Wales: incidence and risk factors. Am J Hematol 2003; 72:248-54.

11. Inman WH. Study of fatal bone marrow depression with special reference to phenylbutazone and oxyphenbutazone. Br Med J 1977; 1:1504-5.

12. Linet MS, Markowitz JA, Sensenbrenner LL, et al. A case-control study of aplastic anemia. Leuk Res 1989; 13:3-11.

13. Marsh JC, Ball SE, Darbyshire P, et al. Guidelines for the diagnosis and management of acquired aplastic anaemia. Br J Haematol 2003 ; 123:782-801.

14. WHO. International monitoring of adverse reactions to drugs: adverse reaction terminology. Uppsala: WHO Collaborating Centre for International Drug Monitoring, Sept 2005.

15. Palace J, Lang B. Epilepsy: an autoimmune disease? J Neurol Neurosurg Psychiatry 2000; 69:711-4. 